(c) American Dairy Science Association, 2004.

\title{
Structure and Physical Properties of Yogurt Gels: Effect of Inoculation Rate and Incubation Temperature
}

\author{
W. J. Lee and J. A. Lucey \\ Department of Food Science, University of Wisconsin-Madison, \\ 1605 Linden Drive, Madison, WI 53706
}

\begin{abstract}
The effects of inoculation rates and incubation temperatures on the physical properties and microstructure of yogurt gels were investigated. A 2-factor experimental design with 3 replicates was used for data analysis. Yogurt gels were made with $0.5,1,2,3$, or $4 \%$ (wt/wt) inoculation rates and incubated at 40 or $\sim 46^{\circ} \mathrm{C}$. Dynamic low amplitude oscillatory rheology was performed to monitor the formation of yogurt gels. Gel permeability and the amount of surface whey were determined. Gel structure was examined by confocal scanning laser microscopy. Higher storage modulus values were observed in yogurt gels made at higher inoculation rates and lower incubation temperatures. Gels made at higher inoculation rates and incubation temperatures exhibited higher yield stress and maximum loss tangent values, respectively. Permeability, pore size, and whey separation of yogurt gels increased with decreased inoculation rate and increased incubation temperature. An increase in the inoculation rate resulted in a decrease in the $\mathrm{pH}$ where the maximum in the loss tangent occurs, presumably reflecting less efficient solubilization of colloidal calcium phosphate (which is a slow process) and the need to attain a lower $\mathrm{pH}$ to complete the solubilization. Significant positive correlations were observed between whey separation and the value of maximum in loss tangent $(\mathrm{r}=0.94)$ and permeability $(\mathrm{r}=0.89)$. Whey separation was negatively correlated with storage modulus $(r=-0.48)$. It was concluded that rearrangements of casein particles in the gel network and the rate at which the solubilization of colloidal calcium phosphate occurred were important driving forces for whey separation and weak gel.
\end{abstract}

(Key words: yogurt, rheology, starter culture, gelation)

Abbreviation key: $\boldsymbol{B}=$ permeability coefficient, $\mathbf{C C P}=$ colloidal calcium phosphate, $\mathbf{G}^{\prime}=$ storage modu-

Received March 8, 2004.

Accepted May 18, 2004.

Corresponding author: J. A. Lucey; e-mail: jalucey@facstaff. wisc.edu. lus, GDL = glucono- $\delta$-lactone, $\mathbf{L} \mathbf{T}_{\max }=$ maximum loss tangent value, $\tan \delta=$ loss tangent, $\gamma_{\text {yield }}=$ yield strain, $\sigma_{\text {yield }}=$ yield stress, $\nu_{\mathrm{pH}}$ gel to 5.0 $=$ acidification rate between gelation time and time at $\mathrm{pH} 5.0, \nu_{\mathbf{p H}} \mathbf{5 . 0}$ to $4.6=$ acidification rate between time at $\mathrm{pH} 5.0$ and $\mathrm{pH} 4.6$.

\section{INTRODUCTION}

Yogurt gels are formed by the fermentation of milk with thermophilic starter bacteria consisting of a mixture of Streptococcus thermophilus and Lactobacillus delbrueckii subsp. bulgaricus (Tamime and Robinson, 1999). In yogurt production, milk is normally heated at a high temperature (e.g., $85^{\circ} \mathrm{C}$ for $30 \mathrm{~min}$ ), which causes the denaturation of whey proteins (i.e., $\beta$-lactoglobulin). Denatured whey proteins interact with $\kappa$ casein on the surface of casein micelles and cross-link caseins and whey proteins (Lucey and Singh, 1997). There is increased casein-casein attraction as the $\mathrm{pH}$ of milk decreases from $\sim 6.6$ (typical milk $\mathrm{pH}$ ) to $\sim 4.6$ during yogurt fermentation, which results in gelation as caseins approach their isoelectric point. Acidification of heated milk also leads to the partial loosening of the yogurt gel network due to the solubilization of colloidal calcium phosphate (CCP) (Lucey, 2002).

Physical properties of yogurt gels, including whey separation, play an important role in quality and consumer acceptance. An understanding of the gelation process during fermentation is critical in manipulating the physical properties of yogurt. However, relatively little work has been performed to study the detailed process of gel formation in yogurt. Dynamic rheology tests, confocal scanning, laser microscopy, permeability, and whey separation are useful methods to study the formation of acid-induced milk gels (Lucey et al., 1998a; Lee and Lucey, 2004).

The rheological properties of acid gels are affected by different starter concentration and incubation temperatures, which directly affect the rate of acidification. van Marle and Zoon (1995) reported that, in acid gels formed by glucono- $\delta$-lactone (GDL), an increase in the acidification rate at the gel point resulted in gels with higher storage modulus $\left(\mathbf{G}^{\prime}\right)$ values compared 
with GDL-induced gels made with lower acidification rates. An increase in the shear modulus of GDL-induced gels and a decrease in the time of the onset of gelation were observed in GDL-induced gels with increased GDL concentrations (Kim and Kinsella, 1989). Kristo et al. (2003) reported that small deformation rheological properties, such as $\mathrm{G}_{\text {max }}$, of fermented milk products were affected by different inoculum concentrations and incubation temperature. There have been several studies on the effect of incubation temperature on physical and micro-structural properties of yogurt gels. The $\mathrm{G}^{\prime}$ values of yogurt gels increased with a decrease in incubation temperature (Lucey et al., 1998b; Kristo et al., 2003; Lee and Lucey, 2004). In contrast with these, Haque et al. (2001) reported that yogurt gels made at a lower incubation temperature exhibited lower $\mathrm{G}^{\prime}$ values of yogurt gels. An increase in the maximum loss tangent values $\left(\mathbf{L} \mathbf{T}_{\max }\right)$ was observed with an increase in incubation temperature (Laligant et al., 2003; Lee and Lucey, 2004). Van Vliet et al. (1997) and Lucey et al. (1998b) also reported that GDL-induced gels made at a higher incubation temperature had higher permeability $(\boldsymbol{B})$ values than gels made at lower incubation temperature. Acid milk gels made at a higher incubation temperature exhibited greater whey separation compared with acid milk gels formed at lower incubation temperature (Lucey et al., 1998a; Lee and Lucey, 2004). High incubation temperature resulted in a decrease in fracture stress of GDL-induced gels and an increase in fracture strain (Lucey et al., 1997; van Vliet et al., 1997).

Different physical properties and microstructures were observed in acid milk gels made with GDL and bacterial culture (Lucey et al., 1998b). These differences could be due to differences in the $\mathrm{pH}$ profiles and rate of acidification between GDL-induced and bacterially induced gels (Lucey et al., 1998b). The integrity of the casein micelle and changes in the internal micellar structure as a function of $\mathrm{pH}$ are important factors that determine the viscoelastic properties of acid-induced gels (Lucey and Singh, 1997). It is likely that the rate of acidification, altered by varying the inoculation rate of the starter culture as well as the incubation temperature, could modify the rheological, physical, and microstructural properties of yogurt gels. The combined effects of inoculation rate and incubation temperature on physical properties, such as permeability, whey separation, and microstructure of yogurt gels, do not appear to have been reported. The incubation temperatures of 40 and $45.7^{\circ} \mathrm{C}$ were chosen, as they cover the range of high and low temperatures often used industrially for yogurt manufacture in the United States.
The objectives of this research were to investigate the combined effects of inoculation rate and incubation temperature on the physical properties and microstructure of yogurt gels, and to study the relationships among physical properties, acidification rate parameters, and microstructure.

\section{MATERIALS AND METHODS}

\section{Preparation of Reconstituted Skim Milk and Heat Treatment}

Low-heat NDM was obtained from Dairy America (Fresno, CA). The whey protein nitrogen index of the low-heat NDM was $7.69 \mathrm{mg}$ of undenatured whey protein/g powder (Bradley et al., 1992). Reconstituted skim milks were prepared by dispersing $12 \mathrm{~g}$ of NDM in $100 \mathrm{~g}$ of distilled and deionized water. NDM dispersions were agitated using a magnetic stirring unit for $3 \mathrm{~h}$ at $\sim 25^{\circ} \mathrm{C}$. Skim milks were heated in a thermostatically controlled water bath at $82.5^{\circ} \mathrm{C}$ for $30 \mathrm{~min}$. Skim milks were cooled to $4^{\circ} \mathrm{C}$ in ice water and stored in a refrigerator $\left(\sim 6^{\circ} \mathrm{C}\right)$ overnight before use.

\section{Yogurt Fermentation}

A commercial yogurt culture (YC-087, Chr. Hansen, Inc., Milwaukee, WI), which consisted of mainly Streptococcus thermophilus and Lactobacillus delbrueckii subsp. bulgaricus with a few other probiotic strains, was used to prepare yogurt. Stock cultures were prepared by transferring $130 \mathrm{mg}$ of freeze-dried culture to $1000 \mathrm{~g}$ of autoclaved reconstituted skim milk and were incubated at $35^{\circ} \mathrm{C}$ for $10 \mathrm{~h}(\mathrm{pH} \sim 4.80)$ before being stored at $-80^{\circ} \mathrm{C}$. Working cultures were made by thawing frozen stock cultures, transferring $0.8 \mathrm{~mL}$ of thawed stock culture to $79.2 \mathrm{~g}$ of autoclaved reconstituted skim milk (10.7\% [wt/wt]), and incubating at $35^{\circ} \mathrm{C}$ for $10 \mathrm{~h}$. Preheat-treated $\left(82.5^{\circ} \mathrm{C}\right.$ for $\left.30 \mathrm{~min}\right)$ skim milk was inoculated with $0.5,1,2,3$, or $4 \%$ (wt/wt) of working culture and incubated at 40 or $45.7^{\circ} \mathrm{C}$ until $\mathrm{pH}$ of the milk reached 4.6. A model PCM 700 Orion Sensor Link system (Orion Research Inc., Beverly, MA), connected to a personal computer, was used to continuously monitor $\mathrm{pH}$ changes during fermentation. The $\mathrm{pH}$ measurements were taken every $5 \mathrm{~min}$ during fermentation. The acidification rate was determined from the linear slopes of the $\mathrm{pH}$ versus time curves ( $\mathrm{pH}$ profiles) (Figure 1) and was expressed as $\mathrm{pH}$ milliunit/min (mU/min).

\section{Rheological Properties}

A Universal Dynamic Spectrometer (Paar Physica UDS 200, Physica Messtechnik GmbH, Stuttgart, Ger- 


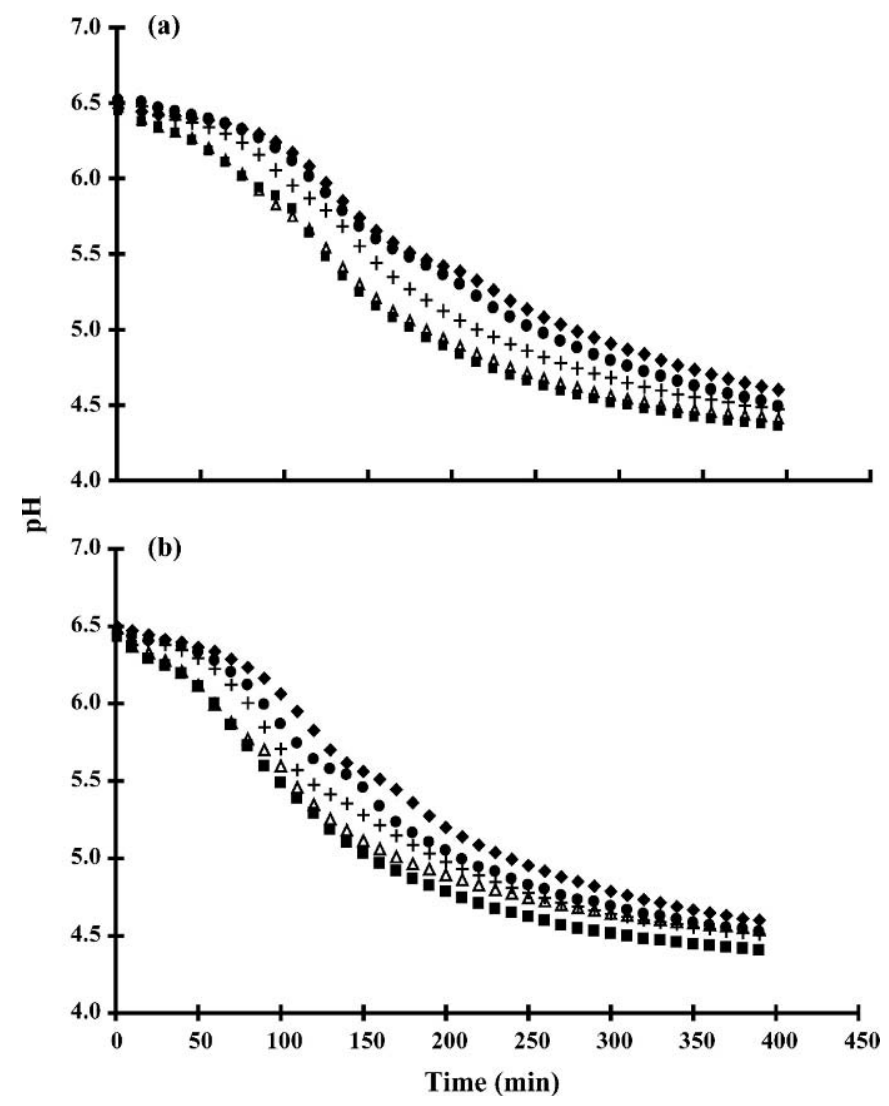

Figure 1. $\mathrm{pH}$ profiles as a function of time for yogurt gels made at $0.5 \%(\diamond), 1 \%(\bullet), 2 \%(+), 3 \%(\triangle)$, and $4 \%(\square)$ inoculation rate and incubated at 40 (a) or at $45.7^{\circ} \mathrm{C}(\mathrm{b})$. Data presented were means of 3 replicates.

many) was used to determine the rheological properties of yogurts. During fermentation, the nondestructive rheological properties of yogurts can be determined by small-amplitude, dynamic oscillation with the measurement of $\mathrm{G}^{\prime}$ and loss tangent $(\tan \delta$ ), which is the ratio of viscous to elastic properties (Roefs et al., 1990; Lucey et al., 1997, 1998b). The cup and bob measuring geometry (Z3 DIN) consisting of 2 coaxial cylinders (diameters 25.0 and $27.5 \mathrm{~mm}$ ) was used. Thirteen milliliters of preheated inoculated milks with $0.5,1,2,3$, or $4 \%$ (wt/wt) working starter culture added were transferred to the rheometer. The milk surface in cup and bob measuring geometry was covered with vegetable oil to prevent evaporation. During fermentation, yogurts were oscillated at a frequency of $0.1 \mathrm{~Hz}$. The applied strain was $1 \%$ which, when applied, did not disrupt the development of the network structure (van Marle and Zoon, 1995). Measurements were taken every 5 min until a $\mathrm{pH}$ of 4.6 was reached. Gelation was arbitrarily defined as the moment when the $\mathrm{G}^{\prime}$ of gels was greater than $1 \mathrm{~Pa}$ (e.g., Lucey et al., 1998b).
The effect of the time scale of deformation on the rheological properties of yogurts was investigated with a frequency sweep test when yogurts were formed. The range of frequency was 0.002 to $1.0 \mathrm{~Hz}$. The large deformation properties of yogurts formed in situ (as above) were determined with the method described by Lucey et al. (1997). A constant shear rate of $0.01 / \mathrm{s}$ was applied to yogurt gels. Yield stress was defined as the point when the shear stress started to decrease.

\section{Permeability}

The permeability coefficient $(B)$ of yogurts was assessed using the method described by Roefs et al. (1990) and Lucey et al. (1998b). Yogurts inoculated with $0.5,1,2,3$, or $4 \%$ (wt/wt) working starter culture were incubated at 40 or $45.7^{\circ} \mathrm{C}$ in open-ended glass tubes (length of $25 \mathrm{~cm}$ and inner diameter of $4 \mathrm{~mm}$ ). When the $\mathrm{pH}$ of milk was 4.6 , glass tubes were vertically placed in a rack, which was located in a transparent measuring vat filled with acid $(\mathrm{pH} 4.6)$ whey. The temperature of acid whey was $30^{\circ} \mathrm{C}$, and the viscosity of acid whey was assumed to be $0.95 \mathrm{mPa} / \mathrm{s}$ (Lucey et al., 1998b). The pressure gradient due to the difference in the level between the top of the yogurt gel in the glass tube and the whey surface in the vat makes whey flow (slowly) through the yogurt gels. The height of whey was determined using a model 2202 digital cathetometer (Precision Tool and Instrument, Bexhillon-Sea, UK). The permeability coefficient (B) was calculated with the following equation:

$$
B=-\left[\ln \frac{\left(h_{\infty}-h_{t 2}\right)}{\left(h_{\infty}-h_{t 1}\right)}\right] \eta H /\left[\rho g\left(t_{2}-t_{1}\right)\right],
$$

where

$B$ is the permeability coefficient,

$h_{\infty}$ is the height of whey in the reference tube, $h_{t 1}$ is the height of whey in tube at time $t_{1}$,

$h_{t 2}$ is the height of whey in tube at time $t_{2}$, $\eta$ is the viscosity of whey,

$h$ is the length of gel, $\rho$ is the density of whey, and $g$ is acceleration due to gravity.

\section{Whey Separation}

The whey separation of yogurt gels was determined using the method of Lucey et al. (1998a). After preheating, $220 \mathrm{~g}$ of milk was inoculated with $0.5,1,2$, 3 , or $4 \%$ (wt/wt) working starter culture; inoculated 
milks were transferred to $250-\mathrm{mL}$ glass volumetric flasks. The milks were incubated in a temperaturecontrolled incubator (model 650F, Fisher Scientific, Hanover, IL) at 40 or $45.7^{\circ} \mathrm{C}$ until $\mathrm{pH}$ of the milk reached 4.6. Eight flasks were used for each treatment. Any whey that was present on the yogurt surface during fermentation was measured. The degree of whey separation was calculated with the following equation: $\%$ whey $=($ weight of whey/total weight of milk $) \times 100$.

\section{Confocal Scanning Laser Microscopy}

The microstructures of yogurt gels were observed using confocal scanning laser microscopy operated in fluorescence mode, as reported by Lee and Lucey (2004). Acridine orange (Sigma Chemical Co., St. Louis, MO) was used as fluorescent protein dye and dissolved in distilled water to a concentration of $0.2 \%$ (wt/wt). Yogurt culture and $300 \mu \mathrm{L}$ of acridine orange were then added to $50 \mathrm{~mL}$ of preheat-treated milk and mixed. A few drops of mixture were transferred to a special slide with a cavity and then held in a temperature-controlled incubator (model 650F, Fisher Scientific, Hanover, IL) at 40 or $45.7^{\circ} \mathrm{C}$ until the $\mathrm{pH}$ of the milk reached 4.6. Yogurt gels were examined at gelation time, the time at which there was a maximum in $\tan \delta$, and the end of fermentation (when $\mathrm{pH}$ of milk reached 4.6) using Bio-Rad MRC 1024 confocal scanning laser microscopy (Hemel Hempstead, UK) with an air-cooled $\mathrm{Ar} / \mathrm{Kr}$ laser. At least 3 representative images were obtained at an excitation wavelength of $488 \mathrm{~nm}$ and with a $60 \times$ oil-immersion objective lens (numerical aperture $=1.4$ ).

\section{Statistical Analysis}

A 2 -factor $(5 \times 2)$ ANOVA with interaction was used to investigate the effect of inoculation rate and incubation temperature on the physical properties and microstructure of yogurt gels. Each experiment was performed in triplicate. Significance was established at $P$ $<0.05$. The statistical analysis system, version 8.02 (SAS Institute Inc., Cary, NC), was used to perform all statistical analyses.

\section{RESULTS}

\section{Small Deformation Rheological Properties}

The changes in $\mathrm{pH}$ of milk as a function of time are shown in Figure 1. During fermentation, the $\mathrm{pH}$ of milk decreased from $\sim 6.5$ to $\sim 4.6$ (Figure 1 ). The $\mathrm{pH}$ of milk decreased slowly for the first $\sim 70 \mathrm{~min}$ and then decreased rapidly (Figure 1). Inoculation rate had a significant effect on the time required to reach $\mathrm{pH} 4.6$
$(P<0.001)$ (Table 1$)$ with the addition of more starter culture to milk resulting in a shorter time to reach $\mathrm{pH}$ 4.6 (Table 2). In yogurt gels incubated at 40 and $45.7^{\circ} \mathrm{C}$, the time from inoculation to $\mathrm{pH} 4.6$ was not significantly different (Table 2). At $40^{\circ} \mathrm{C}$, the $\mathrm{pH}$ profiles for gels with 3 and $4 \%$ starter were virtually identical (Figure 1a).

The $\mathrm{G}^{\prime}$ and $\tan \delta$ profiles of yogurt gels as a function of $\mathrm{pH}$ were shown in Figure 2. When yogurt gels were incubated at $40^{\circ} \mathrm{C}$, the $\mathrm{G}^{\prime}$ value of yogurt gels inoculated with $1,2,3$, or $4 \%$ culture increased just after gelation $\mathrm{pH}$ and increased steadily between $\mathrm{pH} 5.0$ and 4.6 (Figure 2a). However, the gelation profile of yogurt gel inoculated with $0.5 \%$ culture had a clear shoulder between 5.3 and 5.0 (i.e., a flattening of the $\mathrm{G}^{\prime}$ profile before it increased again) (Figure 2a). At an incubation temperature of $45.7^{\circ} \mathrm{C}$, clear shoulders were observed in all the gelation profiles of the yogurt gels (Figure $2 \mathrm{~b}$ ). The gelation profiles of yogurt gels inoculated with $0.5 \%$ culture and incubated at 40 or $45.7^{\circ} \mathrm{C}$ had a slower increase in $\mathrm{G}^{\prime}$ values at $\mathrm{pH}$ values $<4.9$, compared with yogurt gels made with $1,2,3$, or $4 \%$ starter (Figure 2). Gelation profiles (Figure 2) exhibited an increase in $\mathrm{G}^{\prime}$ at $\mathrm{pH}$ values $<5.0$, presumably reflecting reduced electrostatic repulsion and enhanced hydrophobic attractions as the $\mathrm{pH}$ approached the isoelectric point of the caseins.

Two-factor ANOVA results (Table 1) show that inoculation rate had a significant effect on gelation time $(P<0.001)$ and $\mathrm{G}^{\prime}$ value at $\mathrm{pH} 4.6(P<0.001)$ but no effect on $\mathrm{pH}$ at $\mathrm{T}_{\mathrm{Gel}}$ (Table 1). Incubation temperature significantly affected gelation time $(P<0.001), \mathrm{pH}$ at gelation $(P<0.01)$, and $\mathrm{G}^{\prime}$ at $\mathrm{pH} 4.6(P<0.01)$ (Table $1)$. The gelation time significantly increased as inoculation rate decreased, as expected, whereas the $\mathrm{G}^{\prime}$ at $\mathrm{pH} 4.6$ was significantly lower in gels formed with $0.5 \%$ than the other inoculation rates (Table 2). Horne (2003) reported that there was an increase in the maximum value of the complex modulus in GDL gels formed at $25^{\circ} \mathrm{C}$ with increasing GDL concentrations. The gelation time and $\mathrm{G}^{\prime}$ values at $\mathrm{pH} 4.6$ increased with a decrease in incubation temperature (Table 2). Similar results were previously reported for yogurt gels (Lucey et al., 1998b; Lee and Lucey, 2004). No significant differences in gelation $\mathrm{pH}$ of yogurt gels were observed with the different inoculation rates. An increase in the incubation temperature resulted in a slight increase in the gelation $\mathrm{pH}$ (Table 2), in agreement with previous studies (Lucey et al., 1998b; Lee and Lucey, 2004).

An $\mathrm{LT}_{\max }$ was observed in all yogurt gels between pH 5.2 and 5.0 (Figure 2). An increase in inoculation rate shifted $\tan \delta$ profiles to lower $\mathrm{pH}$ values for both incubation temperatures (Figure 2). Inoculation rate significantly affected $\mathrm{pH}$ at $\mathrm{LT}_{\max }(P<0.001)$ but not 
Table 1. Analysis of variance for rheological and physical parameters.

\begin{tabular}{|c|c|c|c|c|c|c|c|c|c|}
\hline & \multicolumn{9}{|c|}{ Independent variables ${ }^{1}$} \\
\hline & \multicolumn{3}{|c|}{ IR } & \multicolumn{3}{|c|}{$\mathrm{T}$} & \multicolumn{3}{|c|}{$\mathrm{IR} \times \mathrm{T}$} \\
\hline & $\mathrm{df}$ & MS & $\mathrm{P}$ & $\mathrm{df}$ & MS & $\mathrm{P}$ & $\mathrm{df}$ & MS & $\mathrm{P}$ \\
\hline $\mathrm{T}_{\mathrm{Gel}}^{2}(\min )$ & 4 & 4202 & $* * *$ & 1 & 5713 & $* * *$ & 4 & 65 & NS \\
\hline $\mathrm{pH}$ at $\mathrm{T}_{\mathrm{Gel}}$ & 4 & 0.002 & NS & 1 & 0.008 & $* *$ & 4 & $<0.001$ & NS \\
\hline $\mathrm{T}_{\mathrm{pH} 4.6}{ }^{3}(\mathrm{~min})$ & 4 & 14488 & $* * *$ & 1 & 97.20 & NS & 4 & 873 & NS \\
\hline $\mathrm{G}^{\prime}$ at $\mathrm{pH} 4.6(\mathrm{~Pa})^{4}$ & 4 & 2900 & $* * *$ & 1 & 3000 & $* *$ & 4 & 210 & NS \\
\hline$\nu_{\mathrm{pH} \text { gel-5.0 }}(\mathrm{mU} / \mathrm{min})$ & 4 & 6.210 & $* *$ & 1 & 0.027 & NS & 4 & 1.061 & NS \\
\hline$\nu_{\mathrm{pH}} 5.0-4.6(\mathrm{mU} / \mathrm{min})$ & 4 & 1.335 & $* *$ & 1 & 5.547 & $* * *$ & 4 & 0.316 & NS \\
\hline $\mathrm{LT}_{\max }$ & 4 & $<0.001$ & NS & 1 & 0.014 & $* * *$ & 4 & $<0.001$ & NS \\
\hline $\mathrm{pH}$ at $\mathrm{LT}_{\max }$ & 4 & 0.013 & $* * *$ & 1 & 0.007 & $*$ & 4 & 0.001 & NS \\
\hline$\sigma_{\text {vield }}^{4}(\mathrm{~Pa})$ & 4 & 1916 & $* * *$ & 1 & 149 & NS & 4 & 210 & NS \\
\hline$\gamma_{\text {yield }}^{4}(-)$ & 4 & 0.008 & $* *$ & 1 & 0.042 & $* * *$ & 4 & 0.003 & NS \\
\hline$B^{4}\left(10^{-13} \mathrm{~m}^{2}\right)$ & 4 & 0.879 & $* * *$ & 1 & 28.04 & $* * *$ & 4 & 0.063 & $* *$ \\
\hline$\%$ Whey $^{4}$ & 4 & 0.385 & $* * *$ & 1 & 45.60 & $* * *$ & 4 & 0.083 & NS \\
\hline
\end{tabular}

${ }^{1} \mathrm{IR}=$ Inoculation rate, $\mathrm{T}=$ Incubation temperature, and $\mathrm{IR} \times \mathrm{T}=$ Interaction between inoculation rate and incubation temperature.

${ }^{2} \mathrm{~T}_{\mathrm{Gel}}=$ Gelation time.

${ }^{3} \mathrm{~T}_{\mathrm{pH} 4.6}=$ Time from inoculation to $\mathrm{pH} 4.6$.

${ }^{4}$ These properties were analyzed when gels were at $\mathrm{pH} \sim 4.6$.

$*, * *, * * *$, significantly different at $P<0.05, P<0.01$, and $P<0.001$, respectively.

the $\mathrm{LT}_{\max }$ value, whereas incubation temperature had a significant effect on $\mathrm{pH}$ at $\mathrm{LT}_{\max }(P<0.05)$ and $\mathrm{LT}_{\max }$ $(P<0.001)$ (Table 1). It was found that inoculation rate had a more pronounced effect on $\mathrm{pH}$ at $\mathrm{LT}_{\max }$, whereas incubation temperature had a dominant effect on $\mathrm{LT}_{\max }$, as indicated by higher mean square values (Table 1). There were no significant differences in $\mathrm{LT}_{\max }$ values of yogurt gels with different inoculation rates (Table 2). The $\mathrm{LT}_{\max }$ values of yogurt gels incubated at $45.7^{\circ} \mathrm{C}$ were significantly higher than those for yogurt gels incubated at $40^{\circ} \mathrm{C}$ (Table 2).
In frequency sweep tests (Figures $3 a$ and $4 a$ ), the $\log G^{\prime}$ values of yogurt gels increased linearly as log frequency increased. The same trends were reported for yogurt gels inoculated with $2 \%$ culture and incubated at 34,40 , and $46^{\circ} \mathrm{C}$ (Lee and Lucey, 2004). Plots with $\log G^{\prime}$ versus log frequency had straight lines, with slopes between 0.15 and 0.17 (Figures $3 a$ and $4 a$ ). There was a slight increase in $\tan \delta$, with increasing frequency for yogurt gels inoculated with 3 or $4 \%$ starter culture and incubated at $40^{\circ} \mathrm{C}$ (Figure $3 \mathrm{~b}$ ). However, the $\tan \delta$ values of yogurt gels inoculated

Table 2. Combined effects of culture inoculation rate and incubation temperature on the rheological and physical parameters of yogurt gels. ${ }^{1,2}$

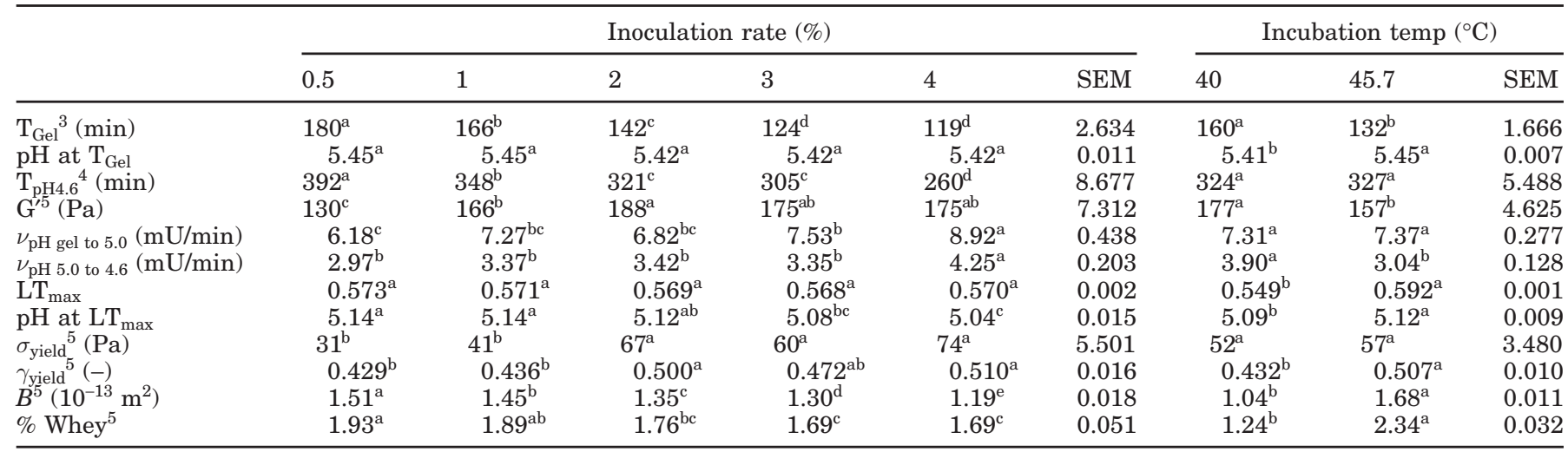

${ }^{1}$ Values with different letters in the same row are significantly different $(P<0.05)$.

${ }^{2} \mathrm{All}$ levels of one factor were used to calculate means for levels of other factors.

${ }^{3} \mathrm{~T}_{\mathrm{Gel}}=$ Gelation time.

${ }^{4} \mathrm{~T}_{\mathrm{pH} 4.6}=$ Time from inoculation to $\mathrm{pH}$ 4.6.

${ }^{5}$ These properties were analyzed when gels were $\mathrm{pH} \sim 4.6$. 


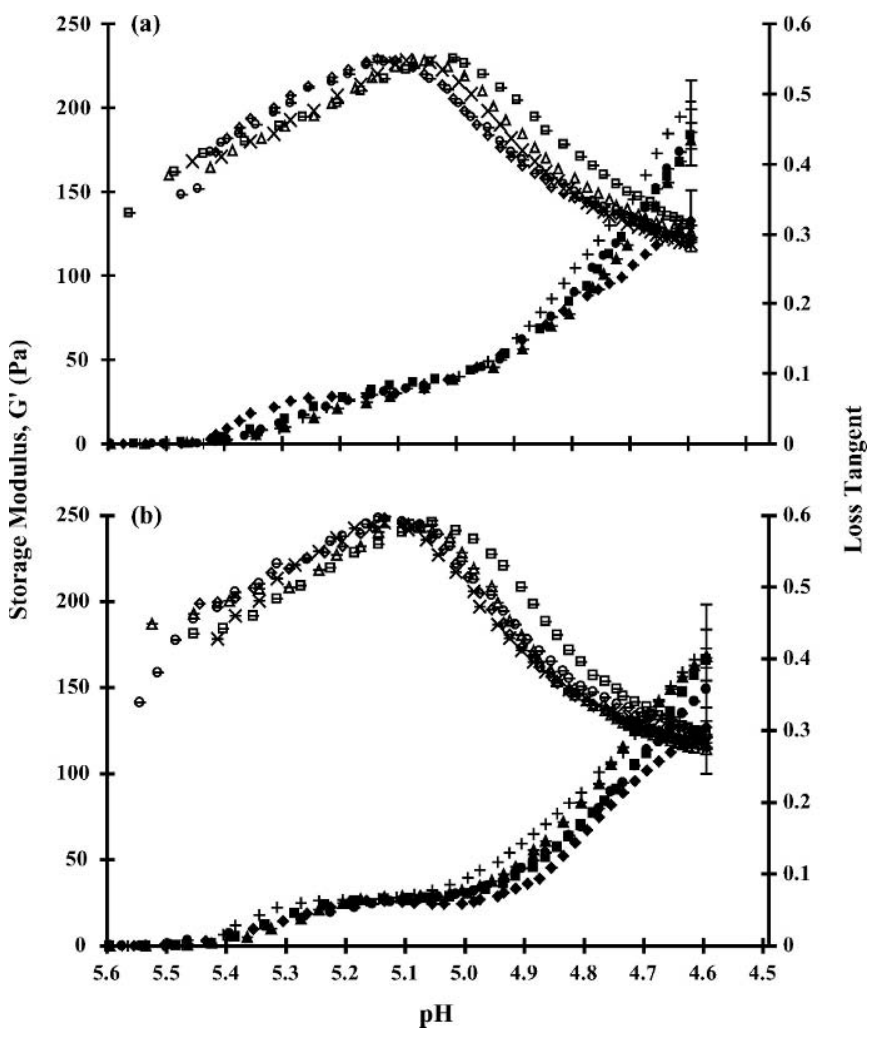

Figure 2. Gelation profiles as a function of $\mathrm{pH}$ for (a) yogurt gels made at $0.5(\diamond, \diamond), 1(\bullet, \bigcirc), 2(+, \times), 3 \%(\boldsymbol{\Delta}, \triangle)$, and $4 \%(\square, \square)$ inoculation rate and incubated at $40^{\circ} \mathrm{C}$ and (b) yogurt gels made at $0.5(\diamond, \diamond), 1(\bullet, \bigcirc), 2(+, \times), 3(\boldsymbol{\Delta}, \triangle)$, and $4 \%(\square, \square)$ inoculation rate and incubated at $45.7^{\circ} \mathrm{C}$. Solid and + symbols indicate the storage modulus $\left(\mathrm{G}^{\prime}\right)$. Open and $\times$ symbols indicate the loss tangent $(\tan \delta)$. Experiments were replicated 3 times. Error bars represent standard deviation.

with $0.5,1$, or $3 \%$ (wt/wt) starter culture and incubated at $40^{\circ} \mathrm{C}$ were independent on frequency. The $\tan \delta$ values of all the yogurt gels incubated at $45.7^{\circ} \mathrm{C}$ increased with an increase in frequency (Figure $4 \mathrm{~b}$ ). A similar trend was observed in yogurt gels inoculated with $2 \%\left(\mathrm{wt} / \mathrm{wt}\right.$ ) and incubated at $45.7^{\circ} \mathrm{C}$ (Lee and Lucey, 2004).

\section{Large Deformation Rheological Properties}

A significant effect of inoculation rate on yield stress $\left(\sigma_{\text {yield }}\right)(P<0.001)$ and yield strain $\left(\gamma_{\text {yield }}\right)(P<0.01)$ was observed, whereas incubation temperature had a significant effect $(P<0.001)$ on $\gamma_{\text {yield }}$ (Table 1$)$. As inoculation rate increased, $\sigma_{\text {yield }}$ and $\gamma_{\text {yield }}$ increased (Table 2). An increase in $\gamma_{\text {yield }}$ was observed in yogurt gels incubated at $45.7^{\circ} \mathrm{C}$ (Table 2). Lucey et al. (1997) and van Vliet et al. (1997) reported that GDL-induced gels formed at high temperature had higher yieldstrain values.
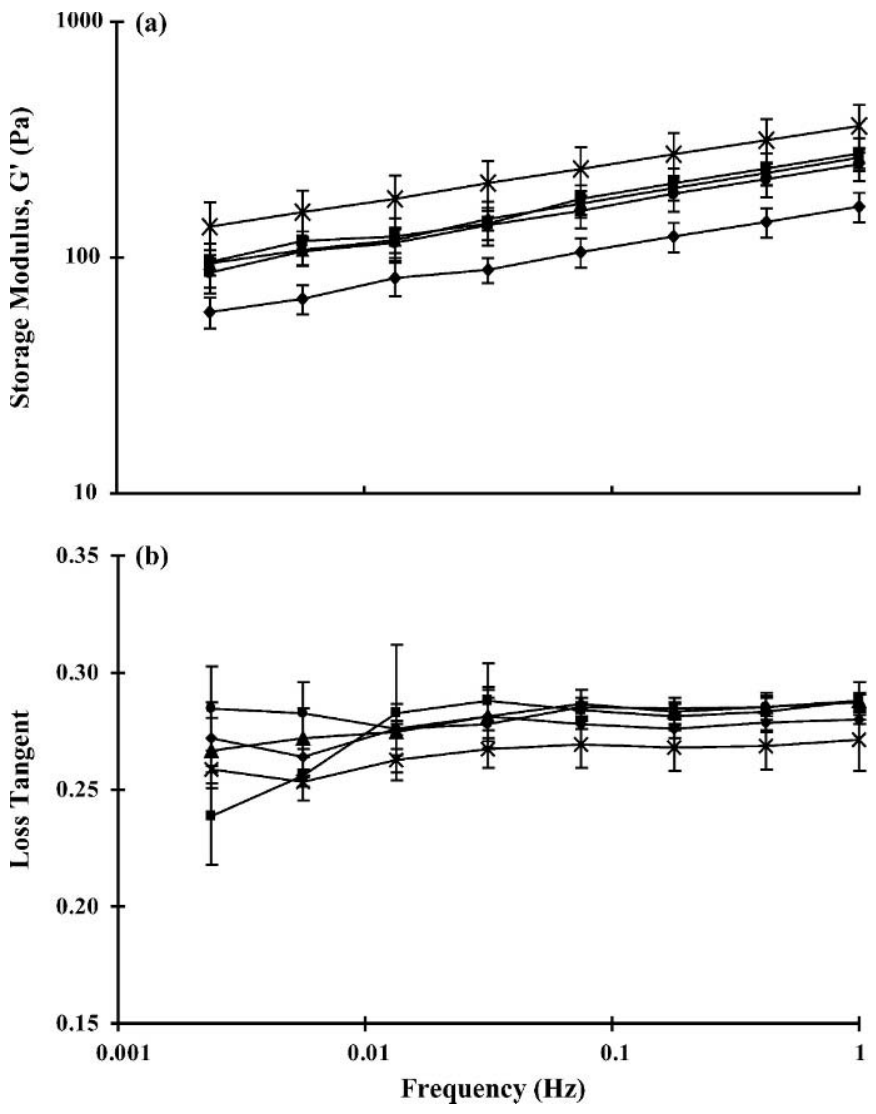

Figure 3. Storage modulus $\left(\mathrm{G}^{\prime}\right)(\mathrm{a})$ and loss tangent (tan $\left.\delta\right)(\mathrm{b})$ as a function of frequency for yogurt gels inoculated at $0.5(\checkmark), 1(-)$ $2(\times), 3(\mathbf{\Lambda})$, and $4 \%(\mathbf{\square})$ and incubated at $40^{\circ} \mathrm{C}$. Error bars represent standard deviation.

\section{Permeability and Whey Separation}

The size of the inhomogenities of gel network (i.e., largest pores) was approximated by permeability measurement (van Dijk and Walstra, 1986). Inoculation rate and incubation temperature had significant effects $(P<0.001)$ on $B$ and whey separation (Table 1$)$. The interaction between inoculation rate and incubation temperature was significant for $B(P<0.01)$ (Table 1). A lower $B$ was observed with an increase in inoculation rate, whereas higher incubation temperature resulted in higher $B$ (Table 2), indicating the presence of larger pores. Higher $B$ values were observed previously in GDL-induced gels and yogurt gels made at a higher incubation temperature (van Vliet et al., 1997; Lucey et al., 1998b; Lee and Lucey, 2004).

Whey separation refers to the spontaneous appearance of whey (serum) on milk gel surfaces and is called wheying-off (Lucey et al., 1998a). Inoculation rate and incubation temperature significantly affected whey separation $(P<0.001)$ (Table 1$)$. Whey separation decreased as inoculation rate increased and incubation 

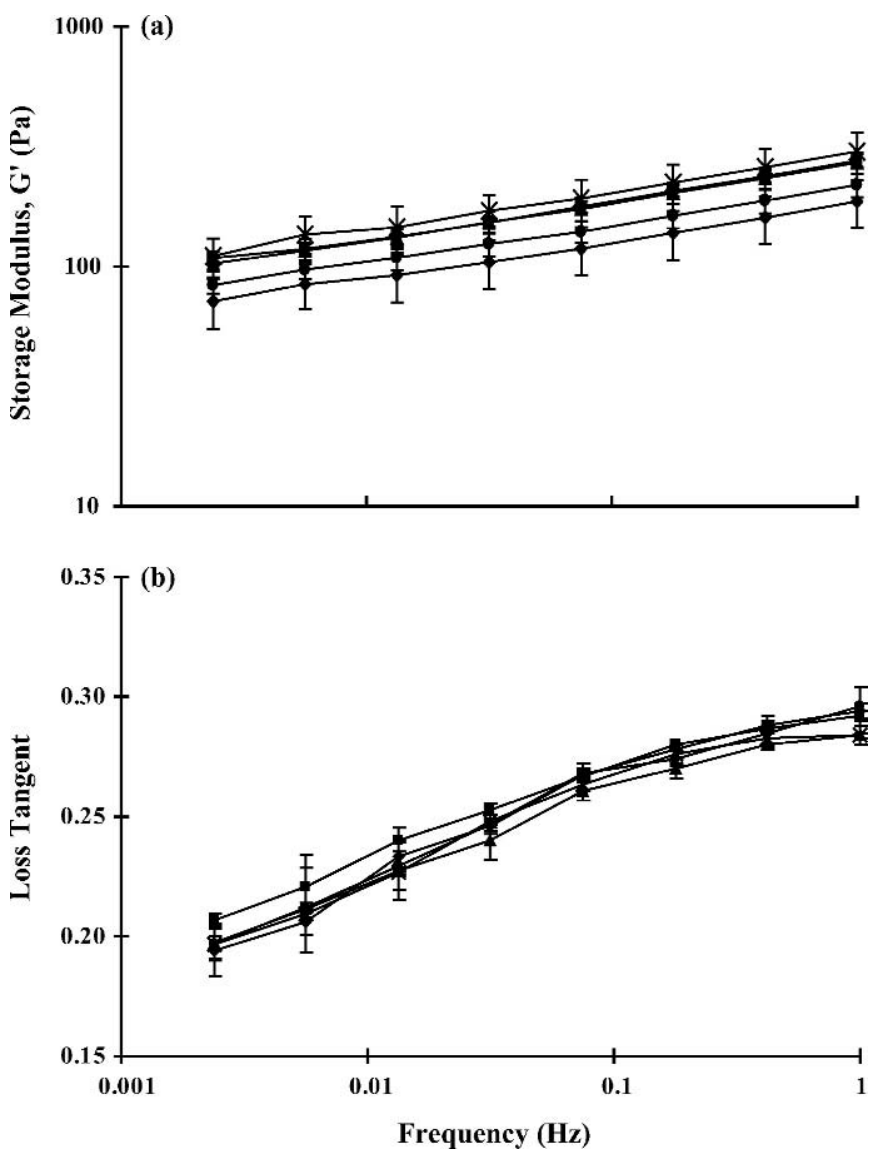

Figure 4. Storage modulus $\left(\mathrm{G}^{\prime}\right)$ (a) and loss tangent ( $\tan \delta$ ) (b) as a function of frequency for yogurt gels inoculated at $0.5(\bullet), 1(-)$ $2(\times), 3(\mathbf{\Delta})$, and $4 \%(\mathbf{\square})$ and incubated at $45.7^{\circ} \mathrm{C}$. Error bars represent standard deviation.

temperature decreased (Table 2). Lucey et al. (1998a) and Lee and Lucey (2004) reported that GDL-induced gels and yogurt gels made at a lower incubation temperature had lower whey separation. It should be noted that incubation temperature was the dominant factor affecting $B$ and whey separation, as indicated by the much higher mean square values (Table 1 ).

\section{Acidification Kinetics}

As was observed in Figure 2, major changes in the $\mathrm{G}^{\prime}$ and $\tan \delta$ curves as a function of $\mathrm{pH}$ occurred in 2 $\mathrm{pH}$ regions-i.e., gelation $\mathrm{pH}$ to $\mathrm{pH} 5.0 ; \mathrm{pH} 5.0$ to $\mathrm{pH}$ 4.6. The acidification rates between gelation time and the time to reach $\mathrm{pH} 5.0\left(\nu_{\mathrm{pH}}\right.$ gel to 5.0$)$ and between the time at $\mathrm{pH} 5.0$ to $\mathrm{pH} 4.6\left(\nu_{\mathrm{pH}} 5.0\right.$ to 4.6$)$ were determined to study the relationship between the acidification rate in these $2 \mathrm{pH}$ regions and the physical properties of yogurt gels. Inoculation rate significantly affected the $\nu_{\mathrm{pH} \text { gel to } 5.0}$ and $\nu_{\mathrm{pH}} 5.0$ to 4.6 , whereas incubation tempera- ture had a significant effect on $\nu_{\mathrm{pH}} 5.0$ to 4.6 (Table 1). It is clear that inoculation rate had a dominant effect on $\nu_{\mathrm{pH}}$ gel to 5.0 , as indicated by the higher mean square values (Table 1). The $\nu_{\mathrm{pH}}$ gel to 5.0 increased with an increase in inoculation rate, whereas no significant

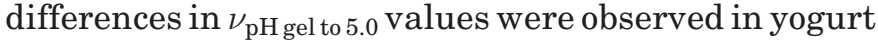
gels made with the different incubation temperatures (Table 2).

\section{Relationships Between Rheological and Physical Properties}

The correlation coefficients between the rheological and physical properties of yogurt gels are shown in Table 3 . There were significant positive correlations between $\mathrm{pH}$ at gelation and $B$, whey separation, and $\mathrm{LT}_{\max }$, with $r$ values of $0.62(P<0.001), 0.47(P<0.01)$, and $0.51(P<0.01)$, respectively (Table 3$)$. The $\mathrm{G}^{\prime}$ value at $\mathrm{pH} 4.6$ was negatively correlated with $B(r=-0.49$, $P<0.01)$ and whey separation $(r=-0.48, P<0.01)$ (Table 3). Strong positive correlations were found between $\mathrm{LT}_{\max }$ and $B(r=0.93, P<0.001)$ and whey separation $(r=0.94, P<0.001)$ (Table 3$)$. The $\nu_{\mathrm{pH}}$ gel to 5.0 negatively correlated with $\mathrm{pH}$ at $\mathrm{LT}_{\max }(r=-0.53$, $P<0.01$ ) (Table 3 ). $\nu_{\mathrm{pH}} 5.0$ to 4.6 had significantly negative correlations with $\mathrm{LT}_{\max }(r=-0.57, P<0.001), B(r=$ $-0.70, P<0.001)$, and whey separation $(r=-0.61, P$ $<0.001$ ) (Table 3). A significant $(P<0.001)$ positive correlation $(r=0.89, P<0.001)$ was observed between $B$ and whey separation (Table 3). Lee and Lucey (2004) reported some similar results. $\sigma_{\text {yield }}$ was positively correlated with $\gamma_{\text {yield }}(r=0.68, P<0.001)$ but negatively correlated with gelation time $(r=-0.67, P<0.001)$ (Table 3). A significant negative correlation $(r=-0.64$, $P<0.001)$ was observed between gelation time and $\gamma_{\text {yield. }}$.

\section{Microstructure}

The micrographs of yogurt gels made with $0.5,3$, or $4 \%$ culture inoculation rates and different incubation temperature $\left(40\right.$ or $45.7^{\circ} \mathrm{C}$ ) are presented in Figures 5 and 6 . In yogurts formed at $40^{\circ} \mathrm{C}$, gels made with $0.5 \%$ culture exhibited a clustered protein network at gelation time, whereas a more interconnected network was observed at the time of $\mathrm{LT}_{\max }$ (Figure $5 \mathrm{a}$ and d). At the end of fermentation ( $\mathrm{pH} 4.6)$, protein clusters became denser and were closer to each other, and yogurt gels exhibited a more branched and interconnected protein matrix compared with yogurt gel at the earlier time points (Figure 5). A similar trend was observed in yogurt gels inoculated with $3 \%$ and incubated at $40^{\circ} \mathrm{C}$ (Figure 5e and h). At $\mathrm{LT}_{\max }$ time and the end of fermentation ( $\mathrm{pH} 4.6$ ), yogurt gel inoculated 
Table 3. Pearson's correlation coefficients between dependent variables.

\begin{tabular}{|c|c|c|c|c|c|c|c|c|c|}
\hline & $\mathrm{T}_{\mathrm{Gel}}{ }^{1}$ & $\mathrm{pH}$ at $\mathrm{T}_{\mathrm{Gel}}$ & $\mathrm{T}_{\mathrm{pH} 4.6}$ & $\mathrm{G}^{\prime}$ & $\nu_{\mathrm{pH} \text { gel to } 5.0}$ & $\nu_{\mathrm{pH}} 5.0$ to 4.6 & $\mathrm{LT}_{\max }$ & $\sigma_{\text {yield }}$ & $B$ \\
\hline$\nu_{\mathrm{pH}}$ gel to 5.0 & $-0.48(* *)$ & $\cdots$ & $-0.81(* * *)$ & $\ldots$ & & $\cdots$ & $\cdots$ & $\ldots$ & $\cdots$ \\
\hline$\nu_{\mathrm{pH}} 5.0$ to 4.6 & $\ldots$ & $\ldots$ & $-0.70(* * *)$ & $0.41(*)$ & 0.69 (***) & $\ldots$ & $\ldots$ & $\ldots$ & $\ldots$ \\
\hline $\mathrm{LT}_{\max }$ & $-0.43(*)$ & $0.51(* *)$ & $\ldots$ & $-0.41(*)$ & $\ldots$ & $-0.57(* * *)$ & $\ldots$ & $\ldots$ & $\ldots$ \\
\hline$\sigma_{\text {yield }}$ & $-0.67(* * *)$ & $\cdots$ & $-0.68(* * *)$ & $0.48(* *)$ & $0.50(* *)$ & $\ldots$ & $\ldots$ & $\begin{array}{l}\ldots \\
\ldots\end{array}$ & $\cdots$ \\
\hline$\gamma_{\text {yield }}$ & $-0.64(* * *)$ & & $\ldots$ & & $\ldots$ & $\ldots$ & $0.56(* *)$ & $0.68(* * *)$ & $\ldots$ \\
\hline$B$ & $\ldots$ & $0.62(* * *)$ & $\ldots$ & $-0.49(* *)$ & $\ldots$ & $-0.70(* * *)$ & $0.93(* * *)$ & $\ldots$ & \\
\hline
\end{tabular}

${ }^{1} \mathrm{~T}_{\mathrm{Gel}}=$ Gelation time.

${ }^{2} \mathrm{~T}_{\mathrm{pH} 4.6}=$ Time from inoculation to $\mathrm{pH} 4.6$.

*, **, ***, significantly different at $P<0.05, P<0.01$, and $P<0.001$, respectively.

with $0.5 \%$ and incubated at $40^{\circ} \mathrm{C}$ was less interconnected and exhibited larger pores (and clusters) compared with yogurt gels inoculated with 3 or $4 \%$ (Figure $5 \mathrm{~g}, \mathrm{~h}$, and i).

In yogurts formed at $45.7^{\circ} \mathrm{C}$ with a $0.5 \%$ inoculation rate at gelation time (Figure 6a), gels had finely dispersed protein clusters, whereas this gel became a tortuous, more obviously clustered protein network at $\mathrm{LT}_{\max }$ time (Figure 6d) and the end of fermentation (Figure $6 \mathrm{~g}$ ). Yogurt gels made with a 3 or $4 \%$ inoculation rate at the gelation time exhibited uniformly distributed protein clusters with some pores (Figure $6 \mathrm{~b}$ and c). At the time of $\mathrm{LT}_{\max }$, yogurt gels made at a 3 or $4 \%$ inoculation rate had changed considerably into more interconnected clusters of aggregated protein particles with larger pores (Figure 6e and f). At the end of fermentation ( $\mathrm{pH} 4.6$ ) (Figure $6 \mathrm{~h}$ and i), protein clusters in yogurt gels made with 3 or $4 \%$ starter came closer to each other and became compact, and pores became larger (Figures $6 \mathrm{~h}$ and i). A more interconnected structure was observed in yogurt gels inoculated with 3 or $4 \%$ starter, compared with yogurt gels made with a $0.5 \%$ inoculation rate (Figure 6 ). It seems that extensive rearrangements occurred in yogurt gel networks made at $45.7^{\circ} \mathrm{C}$ from the point of gelation to $\mathrm{pH} 4.6$ (end of fermentation). Yogurt gels incubated at $40^{\circ} \mathrm{C}$ exhibited more obviously branched and homogeneous interconnected protein networks, and the gels networks underwent less obvious structural changes during fermentation, compared with yogurt gels made at $45.7^{\circ} \mathrm{C}$ (Figures 5 and 6 ).

\section{DISCUSSION}

The effects of inoculation rate and incubation temperature on the rheological, physical properties, and microstructure of yogurt gels were investigated in this study. These are 2 variables routinely selected by yogurt manufacturers to alter yogurt quality attributes. In milk, the integrity of casein micelles is controlled by a localized balance between hydrophobic interaction and electrostatic repulsion (Horne, 1998; Lucey, 2002). As the $\mathrm{pH}$ of milk decreases during fermentation, the CCP within casein micelles is solubilized, especially at $\mathrm{pH}<6.0$, and it is completed by $\mathrm{pH} \sim 5.0$, which leads to the partial rearrangement of the internal structure of casein micelle (Lucey, 2002). Clear shoulders in $\mathrm{G}^{\prime}$ profiles of gels made from heated milk, which corresponded to the region where the $\mathrm{LT}_{\max }$ occurred, were observed in yogurt gels between $\mathrm{pH} 5.2$ and 5.0 (Figure 2). The solubilization of CCP weakens casein-casein interactions and probably contributes to the constant or slightly decreased $\mathrm{G}^{\prime}$ values in this shoulder region and the initial increase in loss tangent (i.e., before a maximum is attained) (Lucey, 2002) (Figure 2). As the $\mathrm{pH}$ of milk approaches the isoelectric point (i.e., $\mathrm{pH}<5.0$ ), electrostatic repulsion decreases, which facilitates enhanced casein-casein attractions due to increased hydrophobic interactions. These factors increase bond formation/strength and thus increase gel stiffness contributing to the increased $\mathrm{G}^{\prime}$ values after the shoulder region (i.e., $\mathrm{pH}<5.0$ ) and the decreased loss tangent (i.e., after the $\mathrm{LT}_{\max }$ ) in gels made from heated milk (Lucey, 2002; Horne, 2003).

At pH 4.6, the $\mathrm{G}^{\prime}$ values of yogurt gels made with $0.5 \%$ starter culture were significantly lower than the other gels (Table 2). No significant differences in $\mathrm{LT}_{\max }$ were observed in yogurt gels made at different inoculation rates, although there was a trend of a slight reduction with higher rates (Table 2). A high $\mathrm{LT}_{\max }$ value has been associated with greater gel rearrangements (Lucey, 2002). The $\mathrm{pH}$ at $\mathrm{LT}_{\max }$ significantly decreased with an increase in inoculation rate (Table 2). The $\nu_{\mathrm{pH}}$ gel to 5.0 had a significant negative correlation with $\mathrm{pH}$ at $\mathrm{LT}_{\max }(r=-0.53, P<0.01)$ (Table 3) (i.e., a faster acidification rate gave a lower $\mathrm{pH}$ at $\mathrm{LT}_{\max }$ ). The solubilization of CCP in milk during acidification is a slow process (Walstra and Jenness, 1984), and it may have required a slightly lower $\mathrm{pH}$ to completely dissolve CCP under a condition of fast acidification (i.e., high 

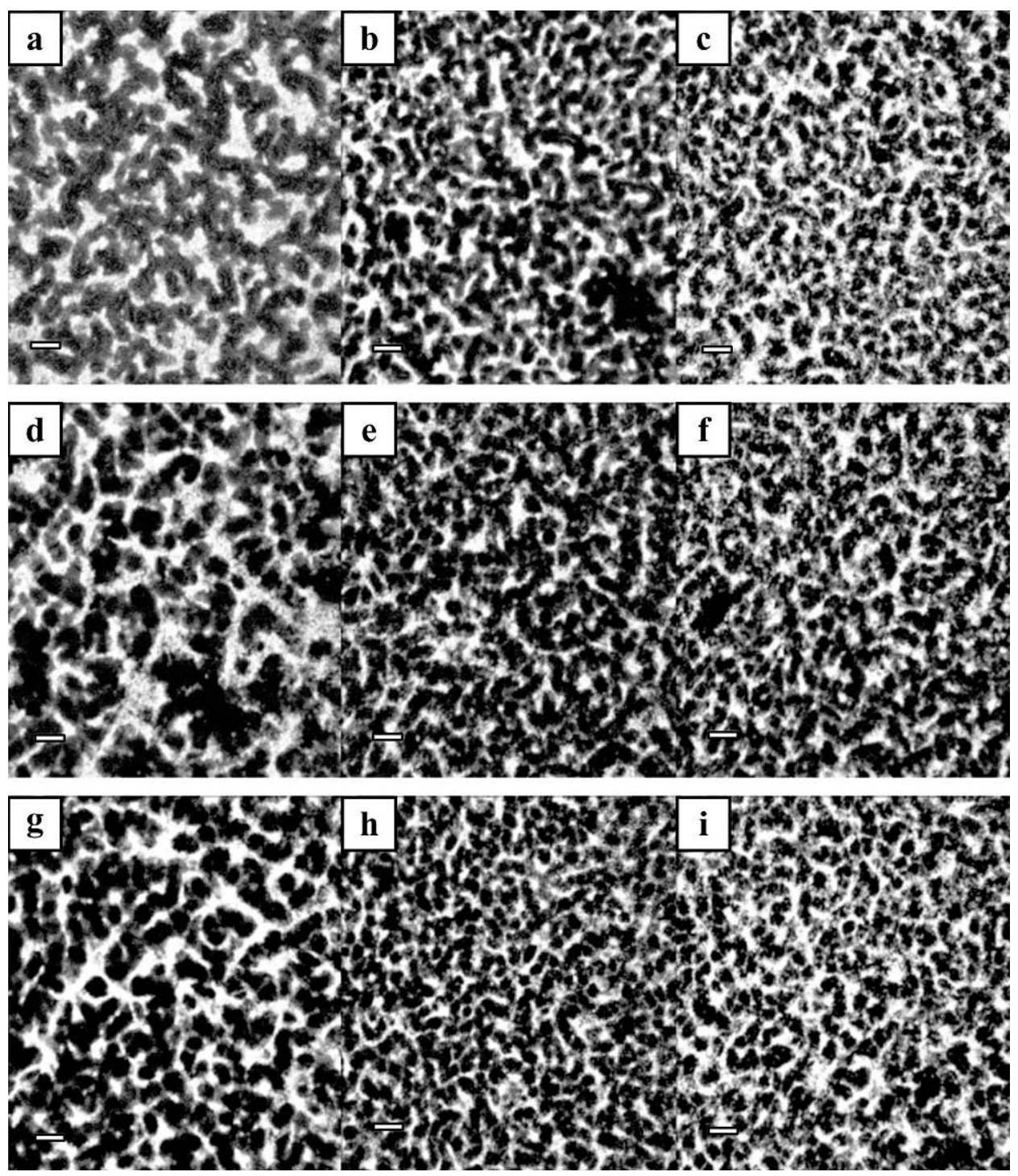

Figure 5. Microstructure of yogurt gels prepared at 0.5 (a, d, and g), 3 (b, e, and h), and 4\% (c, f, and i) inoculation rate and incubated at $40^{\circ} \mathrm{C}$. Confocal scanning laser micrographs were examined at the gelation time $(\mathrm{a}, \mathrm{b}$, and $\mathrm{c})$, time of the maximum in the tan $\delta(\mathrm{d}$, e, and f), and end of fermentation (i.e., when $\mathrm{pH}$ of milk reached 4.6) (g, h, and i). Scale bar $=20 \mu \mathrm{m}$. The protein matrix is white, whereas pores are dark.

inoculation rates may be less efficient in solubilizing $\mathrm{CCP}$, as there would be less time at any particular $\mathrm{pH}$ value during milk acidification). When CCP is dissolved within casein particles, there is an increase in electrostatic repulsion between the exposed phosphoserine residues (Lucey, 2002; Lucey et al., 2003). Yogurt gels made with a higher inoculation rate have a lower $\mathrm{pH}$ at $\mathrm{LT}_{\max }$ (e.g., $\mathrm{pH} \sim 5.0$ ), which would be closer to the isoelectric point of casein compared with yogurt gels formed with a lower inoculation rate. When CCP dissolves at a lower $\mathrm{pH}$, caseins at this lower $\mathrm{pH}$ value may be less sensitive to excessive rearrangements, and this may make stiffer gel networks (i.e., high $\mathrm{G}^{\prime}$ and $\sigma_{\text {yield }}$ values). In yogurt gels made with a lower inoculation rate (e.g., $0.5 \%$ ), the slightly earlier start to the CCP solubilization process and its occurrence at a slightly higher $\mathrm{pH}$ value may have altered the type of casein particles present in the gel network. A higher $\mathrm{pH}$ at $\mathrm{LT}_{\max }$ (e.g., $\mathrm{pH} \sim 5.14$ ) observed in yogurt gels formed at a lower inoculation rate would be far from the isoelectric point of casein, suggesting that there were greater electrostatic repulsions compared with yogurt gels made with a higher inoculation rate. Inoculation rate also changes both the $\mathrm{T}_{\mathrm{Gel}}$ and $\mathrm{T}_{\mathrm{pH} 4.6}$, so it is also possible that some of the observed changes in gel properties are due to the altered kinetics of gel 

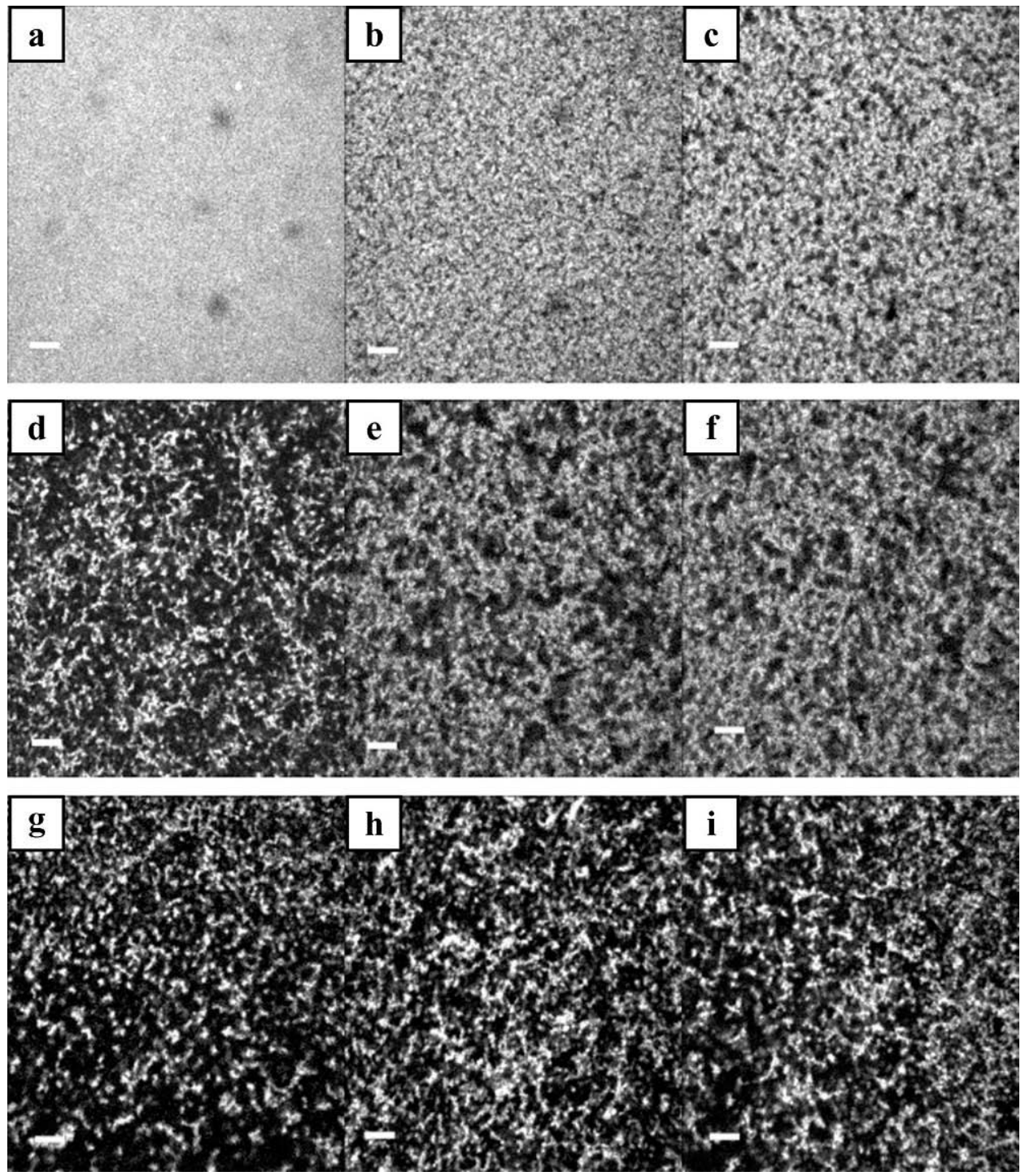

Figure 6. Microstructure of yogurt gels prepared at 0.5 (a, d, and g), 3 (b, e, and h), and $4 \%$ (c, f, and i) inoculation rate and incubated at $45.7^{\circ} \mathrm{C}$. Confocal scanning laser micrographs were examined at the gelation time (a, b, and c), time of the maximum in tan $\delta(\mathrm{d}, \mathrm{e}$, and $\mathrm{f}$ ), and end of fermentation (i.e., when $\mathrm{pH}$ of milk reached 4.6) (g, h, and i). Scale bar $=20 \mu \mathrm{m}$. The protein matrix is white, whereas pores are dark.

formation. The overall result of the slower inoculation rate was the formation of weaker gels that were more prone to rearrangement and whey separation.

The microstructure of yogurt gels made at a lower inoculation rate exhibited larger pores, whereas a more cross-linked and uniformly distributed protein network was observed in yogurt gels made at a higher inoculation rate (Figures 5 and 6 ). A higher $B$ was observed with a decrease in inoculation rate (Table 2 ), which also indicates the presence of larger pores. Lower yield stress of yogurt gels made at a lower inoculation rate may be attributed to large pores (which provided weak spots) and weaker interactions between casein particles (Lucey et al., 1997).

An increase in incubation temperature resulted in a decrease in $\mathrm{G}^{\prime}$ values of yogurt gels at $\mathrm{pH} 4.6$ and an increase in gelation $\mathrm{pH}$ (Table 2 ). When incubation temperature increases, there is an increase in hydrophobic interactions, which contributes to a more compact conformation and a contraction of casein particles. A decrease in the $G^{\prime}$ values of yogurt gels incubated at higher temperatures (a similar effect occurs with the use of higher measuring temperatures for yogurt) can be due to the decreased contact area (and 
therefore interactions) between casein particles (Roefs and van Vliet, 1990; Lucey et al., 1997; Lucey, 2002). When gelation occurs at a higher $\mathrm{pH}$ (i.e., at a higher incubation temperature), the loss of CCP due to a decrease in $\mathrm{pH}$ is less complete, which leads to greater loss of internal structure when the particles are in the gel matrix (Lucey and Singh, 1997; Horne, 2001). This is a possible explanation why the $\mathrm{pH}$ at gelation was negatively correlated with $\mathrm{G}^{\prime}$ and positively correlated with $\mathrm{LT}_{\max }$ (Table 3).

Yogurt gels incubated at $45.7^{\circ} \mathrm{C}$ exhibited higher $\mathrm{LT}_{\max }$ values than those of yogurt gels incubated at $40^{\circ} \mathrm{C}$ (Table 2). A high loss tangent value indicates that there may be an increased possibility of relaxation of bonds in gel network, which may lead to increased rearrangements in gel network (van Vliet et al., 1991; Lucey, 2002). Higher thermal motion of protein particles at high incubation temperatures may alter the aggregation process and contribute to an increased possibility of the gel network to undergo rearrangements (Lee and Lucey, 2004). Yogurt gels made at $45.7^{\circ} \mathrm{C}$ exhibited uniformly dense protein clusters and much less interconnected or branched protein networks compared with yogurt gels at $40^{\circ} \mathrm{C}$ (Figures 5 and 6 ), which probably contributed to extensive rearrangement in the gel network.

An increase in permeability was observed in yogurt gels incubated at higher temperature, indicating that there were larger pores (Table 2). Rearrangements of protein particles in gel networks enhance the formation of cross-links between the protein strands and local breakage of protein strands making up the network (i.e., junctions), which results in the formation of larger pores (van Vliet et al., 1997; van Vliet, 2000). The microstructures of yogurt gels incubated at higher temperature exhibited larger pores (Figures 5 and 6), which is in agreement with high $B$. The permeability increases with time for rennet-induced gels, indicating that the pores became bigger, whereas there is little change in $B$ with time in acid milk gels (van Vliet et al., 1991). After gel formation, the pores in yogurts incubated at $45.7^{\circ} \mathrm{C}$ became larger (Figure 6). Weak yogurt gels have a less stable network, large pores, and exhibit higher whey separation (Lee and Lucey, 2004).

With a decrease in the inoculation rate or an increase in the incubation temperature, there was an increased susceptibility of the gel network to rearrangements, as indicated by the decreased $\mathrm{G}^{\prime}$ and $\sigma_{\text {yield }}$ values and increased $\mathrm{LT}_{\max }$ and $B$. Yogurt gels made at a decreased inoculation rate and increased incubation temperature also had increased whey separation (Table 2). When extensive rearrangements in the protein network occur, this can promote whey separation, which is related to an unstable gel network
(Lucey et al., 1998a; Lucey, 2002). The highly positive correlation between whey separation and $\mathrm{LT}_{\max }(r=$ $0.94, P<0.001)$ and $B(r=0.89, P<0.001)$ (Table 3) also indicates that rearrangement of network structure was associated with enhanced whey separation.

\section{CONCLUSIONS}

This study demonstrated that inoculation rate and incubation temperature are significant processing parameters that affect the physical properties and microstructure of yogurt gels. As inoculation rate increased and incubation temperature decreased, the $G^{\prime}$ and $\sigma_{\text {yield }}$ values increased, and $\mathrm{LT}_{\max }, \mathrm{pH}$ at $\mathrm{LT}_{\max }, B$, and whey separation decreased. During fermentation, the microstructure changes clearly indicated that there were extensive rearrangements of the yogurt gel network incubated at $45.7^{\circ} \mathrm{C}$. It was demonstrated that acidification rate, which affected solubilization of CCP and thus the $\mathrm{pH}$ at $\mathrm{LT}_{\max }$, and rearrangements of casein particles in gel network, were driving forces responsible for whey separation. The use of a combination of an intermediate to high inoculation rate (e.g., $2 \%)$ and low incubation temperature $\left(\sim 40^{\circ} \mathrm{C}\right)$ may provide yogurt with lower whey separation and less textural defects.

\section{ACKNOWLEDGMENTS}

This study was funded by the USDA Cooperative State Research, Education, and Extension Service (CSREES) project WIS04363. The authors wish to thank Kristen Houck for assistance with preparing starter cultures, and Eric Verweiebe for technical assistance with confocal scanning laser microscopy.

\section{REFERENCES}

Bradley, R. L., E. Arnold, D. M. Barbano, R. G. Semerad, D. E. Smith, and B. K. Vines. 1992. Chemical and physical methods. Pages 433-531 in Standard Methods for the Examination of Dairy Products. R. T. Marshall, ed. 16th ed. American Public Health Association, Washington, DC.

Haque, A., R. K. Richardson, and E. R. Morris. 2001. Effect of fermentation temperature on the rheology of set and stirred yogurt. Food Hydrocoll. 15:593-602.

Horne, D. S. 1998. Casein interactions: Casting light on the Black Boxes, the structure in dairy products. Int. Dairy J. 8:171-177.

Horne, D. S. 2001. Factors influencing acid-induced gelation of skim milk. Pages 345-351 in Food Colloids: Fundamentals of Formulation. E. Dickinson and R. Miller, eds. Royal Society of Chemistry, Cambridge, UK.

Horne, D. S. 2003. Casein micelles as hard spheres: Limitations of the model in acidified gel formation. Colloids and Surfaces A: Physicochem. Eng. Aspects 213:255-263.

Kim, B. Y., and J. E. Kinsella. 1989. Rheological changes during slow acid induced gelation of milk by D-glucono- $\delta$-lactone. J. Food Sci. 54:894-898.

Kristo, E., C. G. Biliaderis, and N. Tzanetakis. 2003. Modelling of rheological, microbiological and acidification properties of a 
fermented milk product containing a probiotic strain of Lactobacillus paracasei. Int. Dairy J. 13:517-528.

Laligant, A., M. H. Famelart, D. Paquet, and G. Brulé. 2003. Fermentation by lactic bacteria at two temperatures of pre-heated reconstituted milk. II. Dynamic approach of the gel construction. Lait 83:307-320.

Lee, W. J., and J. A. Lucey. 2004. Rheological properties, whey separation, and microstructure in set-style yogurt: Effects of heating temperature and incubation temperature. J. Texture Stud. 34:515-536.

Lucey, J. A. 2002. Formation and physical properties of milk protein gels. J. Dairy Sci. 85:281-294.

Lucey, J. A., M. E. Johnson, and D. S. Horne. 2003. Perspectives on the basis of the rheology and texture properties of cheese. J. Dairy Sci. 86:2725-2743.

Lucey J. A., and H. Singh. 1997. Formation and physical properties of acid milk gels: A review. Food Res. Int. 30:529-542.

Lucey, J. A., T. van Vliet, K. Grolle, T. Geurts, and P. Walstra. 1997. Properties of acid casein gels made by acidification with glucono$\delta$-lactone. 1. Rheological properties. Int. Dairy J. 7:381-388.

Lucey, J. A., P. A. Munro, and H. Singh. 1998a. Whey separation in acid skim milk gels made with glucono- $\delta$-lactone: Effects of heat treatment and gelation temperature. J. Texture Stud. 29:413-426.

Lucey, J. A., M. Tamehana, H. Singh, and P. A. Munro. 1998b. A comparison of the formation, rheological properties and microstructure of acid skim milk gels made with a bacterial culture or glucono- $\delta$-lactone. Food Res. Int. 31:147-155.
Roefs, S. P. F. M., A. E. A. de Groot-Mostert, and T. van Vliet. 1990. Structure of acid casein gels. 1. Formation and model of gel network. Colloids Surfaces 50:141-159.

Roefs, S. P. F. M., and T. van Vliet. 1990. Structure of acid casein gels. 2. Dynamic measurements and type of interaction forces. Colloids Surfaces 50:161-175.

Tamime, A. Y., and R. K. Robinson. 1999. Yoghurt: Science and Technology. 2nd ed. CRC Press, Boca Raton, FL.

van Dijk, H. J. M., and P. Walstra. 1986. Syneresis of curd. 2. Onedimensional syneresis of rennet curd in constant conditions. Neth. Milk Dairy J. 40:3-30.

van Marle, M. E., and P. Zoon. 1995. Permeability and rheological properties of microbially and chemically acidified skim-milk gels. Neth. Milk Dairy J. 49:47-65.

van Vliet, T. 2000. Structure and rheology of gels formed by aggregated protein particles. Pages 367-377 in Hydrocolloids. Part 1. K. Nishinari, ed. Elsevier Applied Science, Amsterdam, The Netherlands.

van Vliet, T., J. A. Lucey, K. Grolle, and P. Walstra. 1997. Rearrangements in acid-induced casein gels during and after gel formation. Pages 335-345 in Food Colloids: Protein, Lipids, and Polysaccharides. E. Dickinson and B. Bergenstahl, eds. Royal Society of Chemistry, Cambridge, UK

van Vliet, T., H. J. M. van Dijk, P. Zoon, and P. Walstra. 1991. Relation between syneresis and rheological properties of particle gels. Colloid Poly. Sci. 269:620-627.

Walstra, P., and R. Jenness. 1984. Dairy Chemistry and Physics. John Wiley \& Sons, New York, NY. 